\title{
Asymptomatic Carotid Stenosis: Intervention or Best Medical Therapy?
}

\author{
Kamran Gaba ${ }^{1,2} \cdot$ Peter A Ringleb ${ }^{3}$. Alison Halliday ${ }^{2,4}$ \\ Published online: 24 September 2018 \\ (C) The Author(s) 2018
}

\begin{abstract}
Purpose of Review Provide a current overview regarding the optimal strategy for managing patients with asymptomatic carotid artery stenosis.

Recent Findings Carotid endarterectomy (CEA) and carotid artery stenting (CAS) reduce long-term stroke risk in asymptomatic patients. However, CAS is associated with a higher risk of peri-procedural stroke. Improvements in best medical therapy (BMT) have renewed uncertainty regarding the extent to which results from older randomised controlled trials (RCTs) comparing outcomes following carotid intervention can be generalised to modern medical practise.

Summary 'Average surgical risk' patients with an asymptomatic carotid artery stenosis of 60-99\% and increased risk of late stroke should be considered for either CEA or CAS. In patients deemed 'high risk' for surgery, CAS is indicated. Use of an antiplatelet, anti-hypertensive and statin, with strict glycaemic control, is recommended. Results from ongoing large, multicentre RCTs comparing CEA, CAS and BMT will provide clarity regarding the optimal management of patients with asymptomatic carotid artery stenosis.
\end{abstract}

Keywords Carotid endarterectomy $\cdot$ Carotid artery stenting $\cdot$ Best medical therapy $\cdot$ Asymptomatic $\cdot$ Carotid artery stenosis

\section{Introduction}

Thromboembolic stroke is a major cause of morbidity and mortality in the United Kingdom (UK). It has been reported that, annually, more than 100,000 people have a stroke and $12.5 \%$ die within 30 days [1]. Strokes are the fourth largest cause of death and a substantial cause of disability in British adults [1]. In the recent Global Burden of

This article is part of the Topical Collection on Stroke

Kamran Gaba

kamran.gaba@ndph.ox.ac.uk

1 Nuffield Department of Population Health, Medical Research Council Population Health Research Unit, University of Oxford, Richard Doll Building, Old Road Campus, Oxford OX3 7LF, UK

2 Nuffield Department of Population Health, Clinical Trials Service Unit and Epidemiological Studies Unit, University of Oxford, Oxford, UK

3 Department of Neurology, Heidelberg University Hospital, Heidelberg, Germany

4 Nuffield Department of Surgical Sciences, University of Oxford, Oxford, UK
Disease study, the number of global lost disabilityadjusted life years (DALYs) due to cerebrovascular disease had increased by $18.9 \%$ from 1990 [2]. Indeed, by 2010, cerebrovascular disease was the third most common cause of lost DALY globally (compared to fifth most common in 1990) [2]. In the United States of America (USA) alone, strokes are the third most common cause of death, with atherosclerotic stenosis of the carotid artery implicated in $20-25 \%$ of all strokes [3]. Even when asymptomatic, stenosis of the carotid artery has been reported to place an individual at more than $3 \%$ increased risk of having a stroke in the next year (a greater than 50\% increased relative risk) [4].

Carotid endarterectomy (CEA) and carotid artery stenting (CAS) are effective long-term stroke prevention strategies in symptomatic patients. However, uncertainty still remains regarding the optimal technique for long-term prevention of vascular events in asymptomatic patients and, indeed, whether either is sufficiently better than best medical therapy (BMT). This review article outlines the techniques of carotid intervention, presents the evidence for and against the use of CEA and CAS in stroke prevention in asymptomatic patients, summarises the role of BMT and highlights the current research focus in this important subject. 


\section{CEA: the Technique}

CEA can be performed under local anaesthesia (LA) or under general anaesthesia $(\mathrm{GA})$ with or without the use of a shunt. The General Anaesthesia versus Local Anaesthesia for Carotid surgery (GALA) trial reported no difference in stroke or mortality rates between the two types of anaesthesia in patients undergoing CEA [5]. The operation begins with an oblique incision, following the anterior border of the sternocleidomastoid muscle [6]. This is then retracted and the carotid bifurcation is dissected out. Heparin is administered intravenously and the internal, external and common carotid arteries are clamped [6]. A longitudinal arteriotomy is made, extending from the common carotid artery into the internal carotid artery [6]. The plaque is removed and the artery repaired. The repair may include either primary closure of the vessel or placement of a patch to widen the vessel or an eversion CEA may be performed [6]. Similar outcomes (relating to peri-operative major stroke and death rate) have been described between eversion and conventional CEA methods in the Eversion Carotid Endarterectomy versus Standard Trial (EVEREST) randomised clinical trial (RCT) [7]. The incidence of early carotid artery occlusion and restenosis at mean follow-up of 14.9 months was also similar between the two groups [7].

However, performing CEA also has local risks: cranial nerve injury, peri-operative myocardial infarction (MI) and postoperative haematoma are well-recognised potential complications [8]. Moreover, patients with concurrent coronary artery disease and contralateral carotid artery occlusion are considered high risk for CEA $[9,10]$. Other factors that make CEA more technically difficult include a high carotid bifurcation, recurrent stenosis after previous CEA, contralateral cranial nerve palsies, radical neck dissection and previous radiation to the area [8]. In these patients, CAS may be a feasible alternative [11-13].

\section{CAS: the Technique, Indications and Challenges}

CAS is usually carried out under LA. A catheter is inserted percutaneously into the common femoral artery (or rarely via a brachial or even direct carotid access) and advanced until the common carotid artery is reached [6]. A guidewire is deployed across the stenosis so that a stent can be placed and a balloon may be used to expand the stent [6]. Embolic protection devices (EPDs) are often used to try to minimise embolisation of atherosclerotic material distal to the stenosis, preventing neurological ischaemia [6]. Carotid flow reversal can also be used to minimise the peri-procedural stroke risk.

CAS is less invasive than CEA and it may be performed in patients with co-morbidities that confer an unjustifiably high surgical risk for CEA whilst being able to potentially treat lesions that are inaccessible by surgery. However, various studies have shown that CAS may carry a higher stroke risk in symptomatic patients compared to asymptomatic patients $[14,15]$.

Registry data (as well as post hoc analysis of the RCTs comparing CAS and CEA in symptomatic patients) demonstrate that increased age is an independent predictor of poor outcome after CAS $[15,16]$. This may be due to atherosclerotic disease being more advanced in old age, carotid vessels being more tortuous and plaques in the aortic arch being commoner. Engaging the common carotid artery may be technically challenging, causing distal embolisation of plaque and subsequent stroke or death.

Similarly to CEA, a learning curve also exists in acquiring the skills necessary to perform CAS. The Pro-CAS registry demonstrated a positive volume-outcome relationship: in centres performing less than $50 \mathrm{CAS}$ procedures per year, the stroke or death rate was higher (at 5.9\%) compared with centres performing more than $150 \mathrm{CAS}$ procedures per year, whose stroke or death rate was 3.0\% [14]. A similar relationship was demonstrated in the Stent-Protected Angioplasty versus Carotid Endarterectomy-1 (SPACE-1) study: centres performing less than 50 CAS procedures per year had a stroke or mortality rate of $4.6 \%$ whereas it was $2.9 \%$ in centres performing more than 50 CAS procedures per year [17]. This was also supported by the Carotid Stenting Trialists' Collaboration (CSTC) who pooled data from three randomised trials: the Endarterectomy Versus Angioplasty in patients with Symptomatic Severe Carotid Stenosis (EVA-3S) trial, the aforementioned SPACE1 trial and the International Carotid Stenting Study (ICSS) [18-21]. The CSTC group reported that the 30-day risk of stroke or death was not related to operator lifetime experience but it was higher in patients treated by interventionalists who performed less than 6 CAS procedures per annum [18].

\section{CEA in Asymptomatic Patients: the Evidence}

Major RCTs comparing CEA versus BMT in asymptomatic patients are the Veterans Affairs (VA) Cooperative Study, the Asymptomatic Carotid Atherosclerosis Trial (ACAS) and the Asymptomatic Carotid Surgery Trial-1 (ACST-1), randomising patients between the 1980s and early 2000 s [22-24]. The VA study $(n=444)$ reported an absolute risk reduction (ARR) in ipsilateral neurological events of $12.6 \%$ after CEA compared to BMT ( $8.0 \%$ versus $20.6 \%$ respectively; $p<0.01$ ), in patients with a mean follow-up of almost 4 years [22]. However, there was no difference in the combined endpoint of stroke and death [22]. The ACAS study $(n=$ 1662) reported that CEA reduced the 5-year risk of the combined endpoint of ipsilateral stroke and any peri-operative stroke or death by $53 \%$ compared to BMT $(5.1 \%$ versus $11.0 \%$ respectively; $p=0.004)$ [23]. The ACST-1 $(n=3120)$ reported an ARR in stroke risk (when including peri-operative risks) of $4.1 \%$ at 5 years (CEA $6.9 \%$, BMT 10.9\%; $p=0.0001$ ) 
and $4.6 \%$ at 10 years (CEA $13.4 \%$, BMT $17.9 \% ; p=0.009$ ) $[24,25]$. This reduction in stroke risk was slightly improved when peri-operative events were excluded and half the reduction was in disabling and fatal strokes [25]. However, effective BMT was not available when these RCTs were undertaken.

The main findings of the above RCTs are summarised in Table 1.

\section{CAS in Asymptomatic Patients: the Evidence}

Unfortunately, the RCTs carried out comparing CEA with CAS have produced unreliable results due to heterogeneous patient populations, different endpoints being used, a variety of endovascular devices being used, varying use of EPDs between studies and varied endovascular experience of interventionalists participating in the RCTs.

The Stenting and Angioplasty with Protection in Patients at High Risk for Endarterectomy (SAPPHIRE) trial compared CAS with CEA in 334 patients at high operative risk [26]. This RCT included both symptomatic $(n=97)$ and asymptomatic $(n=237)$ patients [26]. Overall, there was no statistically significant difference in the composite endpoint of death, stroke or MI at 30 days with fewer CAS patients receiving re-intervention at 1 year than those undergoing CEA [26]. In asymptomatic patients specifically, the cumulative incidence of death, stroke or MI at 30 days was $5.4 \%$ for those receiving CAS and $10.2 \%$ undergoing CEA $(p=0.20)$ [26]. The equivalent outcome at 1 year was $9.9 \%$ in the CAS group and $21.5 \%$ in the CEA group and was statistically significant $(p=0.02)$ [26]. This is likely to be explained by the SAPPHIRE population having greater co-morbidities (75.5\% of patients undergoing CEA had coronary artery disease), leading to a significantly higher rate of MI in the CEA compared to the CAS group $(p=0.03)$ [26]. At 3 years, stroke rates were comparable between asymptomatic patients undergoing CEA and CAS (9.2 and 10.3\% respectively) whilst the combined endpoint of death, stroke or MI was also similar (29.2\% versus $21.4 \%$ respectively) [27].

The Carotid Revascularisation Endarterectomy versus Stenting Trial-1 (CREST-1) was a large multicentre RCT, including 1321 symptomatic and 1181 asymptomatic patients [28]. Each surgeon and interventionalist was required to meet a minimum set of standards for experience and performance whilst EPDs were used in $96.1 \%$ of patients [28]. Overall, there was no statistically significant difference in the rates of the combined endpoint of stroke, MI or death within 30 days between CAS and CEA [28]. In asymptomatic patients, the combined endpoint at 30 days was $3.5 \%$ after CAS and $3.6 \%$ following CEA (hazard ratio (HR) $1.02(0.55-1.86) ; p=0.96)$ [28]. The peri-procedural stroke rate in asymptomatic patients undergoing CEA and CAS was $1.4 \%$ and $2.5 \%$ respectively (HR $1.88(0.79-4.42) ; p=0.15)$ [28]. Whilst the overall periprocedural incidence of stroke or death was statistically significantly higher after CAS than after CEA in symptomatic patients $(p=0.02)$, this was not statistically significant for asymptomatic patients $(p=0.15)$ [28]. There were also more MIs following CEA in symptomatic than asymptomatic patients [28]. At 2 years, there was no statistically significant difference in the composite outcome of re-stenosis or reocclusion and, at 4 years, there was no difference in ipsilateral stroke or death rate between CAS and CEA groups [28]. In asymptomatic patients specifically, the 4-year rate of stroke or death was $4.5 \%$ after CAS and $2.7 \%$ following CEA $(p=0.07)$ [28]. By 5 years, the rate of stroke in asymptomatic patients was $2.5 \%$ after CAS and $2.7 \%$ following CEA [29••]. Increased age, female sex, hypertension, diabetes and dyslipidaemia were independent predictors of re-stenosis or re-occlusion at 2 years after CAS whilst smoking was statistically significantly associated with re-stenosis after CEA [30]. At 10 years of follow-up, there was no statistically significant difference in the composite endpoint of stroke, MI or death and subsequent ipsilateral stroke between CAS and CEA groups in either symptomatic or asymptomatic subgroups

Table 1 Summary of the evidence for the role of CEA in long-term stroke prevention in asymptomatic patients

\begin{tabular}{llllll}
\hline Clinical trial & Years of recruitment & Degree of stenosis & Number of patients & Follow-up (years) & Findings \\
\hline VA & $1983-1987$ & $250 \%$ & 4.0 & $\begin{array}{l}\text { Ipsilateral TIA, amaurosis fugax or stroke } \\
\text { CEA } 8.0 \%, \text { BMT 20.6\%; } p<0.001\end{array}$ \\
ACAS & $1987-1993$ & $\geq 60 \%$ & 1662 & 2.7 & $\begin{array}{l}\text { Peri-procedural stroke or death, and } \\
\text { post-operative ipsilateral stroke }\end{array}$ \\
& & & & $\begin{array}{l}\text { CEA 5.1\%, BMT } 11.0 \% ; p=0.004 \\
\text { Any stroke or peri-operative death } \\
\text { CEA } 6.9 \%, \text { BMT } 10.9 \% ; p=0.0001\end{array}$ \\
& $1993-2003$ & 3120 & & 5.0 & $\begin{array}{l}\text { Any stroke or peri-operative death } \\
\text { CEA } 13.4 \%, \text { BMT } 17.9 \% ; p=0.009\end{array}$ \\
\hline
\end{tabular}

Abbreviations: ACAS Asymptomatic Carotid Atherosclerosis Study, ACST-1 Asymptomatic Carotid Surgery Trial 1, BMT best medical therapy, CEA carotid endarterectomy, TIA transient ischaemic attack, VA Veterans Affairs Cooperative Study 
[29••]. In asymptomatic patients, the rates of post-procedural ipsilateral strokes were similar at 5 and 10 years, regardless of the modality of revascularisation used [29・•]. Therefore, symptom status may predict peri-procedural risk of complications but does not appear to be relevant in the long term.

The Asymptomatic Carotid Trial-1 (ACT-1) reported that CAS was non-inferior to CEA with regard to the composite endpoint of death, stroke or MI within 30 days of the procedure in 1453 asymptomatic patients with severe carotid artery stenosis $(3.3 \%$ versus $2.6 \%$ respectively; $p=0.60)$ [31••]. Periprocedural death was equivalent between CAS and CEA groups $(0.1 \%$ versus $0.3 \%$ respectively; $p=0.60)$, as was periprocedural MI $(0.5 \%$ versus $0.9 \%$ respectively; $p=0.41)$ $[31 \bullet \cdot$. CEA halved the risk of peri-procedural stroke compared to CAS, though this was not statistically significant $(1.4 \%$ versus $2.8 \%$ respectively; $p=0.23$ ) [31 $\bullet$ ]. By 1 -year follow-up, $3.8 \%$ of patients receiving CAS and $3.4 \%$ of patients undergoing CEA had died or experienced a stroke or MI and, by 5 years, the ipsilateral stroke rate was $2.2 \%$ after CAS and $2.7 \%$ following CEA $(p=0.51)[31 \bullet \cdot$. This RCT reported its findings recently and broadly supports the findings of CREST-1. However, its results may not be fully generalisable to contemporary practise as they only used one type of stent and EPD [28].

The main findings of the above RCTs are summarised in Table 2.

\section{BMT in Asymptomatic Patients: Recommendations}

Many RCTs listed above were carried out before the advancement of modern medical therapies (e.g. widespread prescribing of statins) and, as such, it is unclear what effect this might have on outcomes. Most patients with carotid artery stenosis today should be prescribed a statin, anti-platelet agent and a blood pressure-modifying agent [32••]. However, in the early years of recruitment in the ACST-1, less than $10 \%$ of patients were taking lipid-lowering therapy at baseline [25]. This increased to $80 \%$ by the end of follow-up [25]. This could have potentially confounded outcomes as it has been demonstrated that a $1-\mathrm{mmol} \mathrm{L}^{-1}$ reduction in low-density lipoprotein (LDL) cholesterol reduces the 5 -year risk of stroke by approximately $25 \%$ [33-35]. This might explain why statin use was associated with a halving of the risk of stroke following CEA in the ACST-1 [24, 25]. However, irrespective of statin use, CEA still halved the stroke rate in the ACST-1 [24, 25].

The recent guidelines published by the European Society for Vascular Surgery (ESVS) in 2018 recommend that a healthy diet, smoking cessation and physical activity should all be instituted for risk factor reduction in patients with known asymptomatic carotid artery stenosis [36••]. Lowdose aspirin was also recommended as the anti-platelet agent of choice despite a lack of adequately powered studies (with insufficient follow-up) showing benefits of anti-platelet agents in patients with asymptomatic carotid artery stenosis and conflicting results reported in RCTs [37, 38, 39••, 40]. Patients who are intolerant of aspirin should be prescribed clopidogrel instead [36••]. Anti-platelet therapy should be used periprocedurally and long-term following both CEA and CAS, with dual anti-platelet therapy recommended for at least 1 month post-CAS [36••].

Lipid-lowering therapy in the form of statins has also been recommended for long-term prevention of cardiovascular disease in asymptomatic patients [36••]. This is evidence-based as a Cochrane review demonstrated a significant reduction in allcause mortality, fatal/non-fatal strokes and revascularisation in patients randomised to statins [41]. The pharmacological agents that have been widely prescribed in RCTs are

Table 2 Summary of the evidence for the role of CAS in long-term stroke prevention, compared to CEA, in asymptomatic patients

\begin{tabular}{|c|c|c|c|c|}
\hline Clinical trial & Years of recruitment & Number of patients & Follow-up (years) & Findings \\
\hline SAPPHIRE* & 2000-2002 & 237 & 3.0 & $\begin{array}{l}\text { Peri-procedural MI, stroke, death and } \\
\text { post-procedural ipsilateral stroke and death } \\
\text { CEA } 29.2 \% \text {, CAS } 21.4 \%\end{array}$ \\
\hline CREST-1* & 2000-2008 & 1181 & 10.0 & $\begin{array}{l}\text { Peri-procedural MI, stroke, death and } \\
\text { post-procedural ipsilateral stroke } \\
\text { CEA } 5.4 \% \text {, CAS } 6.1 \% ; p=0.95 \\
\text { Peri-procedural MI, stroke, death and } \\
\text { post-procedural ipsilateral stroke } \\
\text { CEA } 10.1 \% \text {, CAS } 9.6 \%\end{array}$ \\
\hline ACT-1 & 2005-2013 & 1453 & 5.0 & $\begin{array}{l}\text { Post-procedural ipsilateral stroke } \\
\text { CEA } 2.7 \% \text {, CAS } 2.2 \% ; p=0.51\end{array}$ \\
\hline
\end{tabular}

Abbreviations: ACT-1 Asymptomatic Carotid Stenosis 1, CAS carotid artery stenting, CEA carotid endarterectomy, CREST-1 Carotid Revascularisation Endarterectomy versus Stenting Trial, MI myocardial infarction, SAPPHIRE Stenting and Angioplasty with Protection in Patients at High Risk for Endarterectomy

*Subgroup analysis 
atorvastatin and rosuvastatin and attempts should be made to achieve targets of either a $50 \%$ reduction in LDL cholesterol or a level less than $1.8 \mathrm{mmol} \mathrm{L}^{-1}\left(70 \mathrm{mg} \mathrm{dL}^{-1}\right)$ [42-44].

Whilst the effect of anti-hypertensive therapy on stroke prevention in patients with asymptomatic carotid artery stenosis has not been formally evaluated, treatment of high blood pressure is associated with reduction and regression of carotid artery stenoses [45]. Indeed, a meta-analysis demonstrated a reduction in stroke risk that was proportional to lowering of systolic blood pressure and a Chinese RCT reported reduced stroke risk associated with use of enalapril $[46,47 \bullet]$. In reality, the type of pharmacological agent used is less important than achieving the target of reducing blood pressure below 140/90 $\mathrm{mm} \mathrm{Hg}$ in non-diabetic patients with asymptomatic carotid artery stenosis [48]. Blood pressure should be maintained below 180/ $90 \mathrm{~mm} \mathrm{Hg}$ peri-procedurally following CEA and CAS [36••].

In diabetic patients with asymptomatic carotid artery stenosis, tight glycaemic control is recommended as these patients are at increased risk of stroke [49]. Therefore, it is important that risk factor reduction and BMT is appropriately prescribed in diabetic patients. In a study of type II diabetes patients, the use of lipidlowering therapy, anti-platelet agents and anti-hypertensive medications was associated with a $60 \%$ reduction in cardiovascular events and deaths [50]. Moreover, the UK Prospective Diabetes Study reported that intensive blood pressure control in diabetic patients reduced the relative risk of stroke by $44 \%$ compared to patients with a higher blood pressure [51]. The joint European Society for Hypertension/European Society of Cardiology guidelines (2013) recommend that the target blood pressure in diabetic patients with asymptomatic carotid artery stenosis should be less than 140/85 $\mathrm{mm} \mathrm{Hg}$ [52].

\section{Other Considerations}

Carotid intervention is now much safer than at any time in the past with CEA outcomes significantly improved when patients are operated on by vascular surgeons compared with cardiothoracic surgeons, general surgeons or neurosurgeons [53-55, 56•, 57-59]. This might simply reflect that vascular surgeons perform CEAs more frequently than other specialists and are more familiar with the operation. This positive volume-outcome relationship in CEA has been proven to reduce both mortality and combined mortality/stroke [60•]. This trend of sub-specialisation has not been reflected when vascular surgeons, interventional radiologists, neurosurgeons and interventional neuroradiologists performed CAS in the CREST-1 [28]. This was shown to affect outcomes, with vascular surgeons and interventional radiologists having worse CAS outcomes than interventional neuroradiologists or interventional cardiologists [61]. This may reflect the varying complexity of cases referred to each specialty or the lack of experience with catheter-based procedures in some specialties at the time of the CREST-1. By contrast, the ACAS employed such strict credentialing that $40 \%$ of all applicants were rejected from participating in the $\mathrm{RCT}$ due to an unfavourable safety record [23]. So, these RCT findings may not be generalisable to contemporaneous practise.

Use of EPDs may reduce the peri-procedural stroke rate following CAS. A systematic review reported a reduced 30 day death or stroke rate from 5.5 to $1.8 \%$ in patients undergoing CAS without and with EPDs respectively [62]. Data from a large registry have also confirmed the finding that EPDs reduce the death or stroke rate in patients undergoing CAS, with the use of EPDs being an independent protective factor [63]. Varying use of EPDs in the RCTs, in contrast to modern practise, must be taken into account when interpreting findings.

Novel medical therapies may also show benefit in reducing the long-term stroke risk in asymptomatic patients. A subgroup analysis of the recently completed Cardiovascular Outcomes for People using Anticoagulation Strategies (COMPASS) RCT showed that addition of low-dose rivaroxaban to aspirin (in 1919 patients with previous carotid artery revascularisation or asymptomatic carotid artery stenosis of at least $50 \%$ ) reduced the overall major adverse cardiovascular event rate (HR $0.63(0.38-1.05 ; p=0.07)$ [64••]. This was not at the expense of an increased bleeding risk [64••]. Therefore, whilst this subgroup analysis was inadequately powered to provide meaningful conclusions, larger RCTs may reveal a significant effect of adding low-dose rivaroxaban to aspirin in long-term stroke prevention.

\section{Conclusions and Future Perspectives}

It is clear that both CEA and CAS reduce the long-term stroke risk in asymptomatic patients. With regard to peri-procedural outcomes, a recent meta-analysis of 3901 asymptomatic patients randomly assigned to CEA $(n=1585)$ or CAS $(n=$ 2316) reported that CAS was associated with a significantly higher risk of peri-procedural stroke than CEA (2.6\% versus $1.3 \%$ respectively; $p=0.04$ ) [65••]. This was largely driven by more minor strokes following CAS than CEA (2.2\% versus $1.0 \% ; p=0.05)[65 \bullet \cdot]$. Rates of death, major stroke, ipsilateral stroke and MI were comparable between CEA and CAS $[65 \bullet \bullet]$.

ESVS guidelines (2018) therefore recommend that patients with an 'average surgical risk' and an asymptomatic carotid artery stenosis of 60-99\% should be considered for CEA only in the presence of one or more characteristics that may be associated with an increased risk of late ipsilateral stroke $[36 \bullet \bullet$. According to this guideline, imaging/clinical criteria that might confer an increased risk of stroke on BMT include silent infarction on computerised tomography, stenosis progression, large plaque area, plaque echolucency, intra-plaque 
haemorrhage on magnetic resonance imaging, impaired cerebral vasoreactivity, spontaneous embolisation on transcranial Doppler ultrasound and/or history of contralateral transient ischaemic attack [36••]. CAS is also a feasible alternative in these patients [36••]. However, in selected patients who are deemed 'high risk' for surgery with an asymptomatic carotid artery stenosis of $60-99 \%$, CAS is indicated [36••]. Again, these patients must be deemed at increased risk of late ipsilateral stroke [36•*]. Requirement for any intervention is a documented peri-procedural risk of stroke/death of less than $3 \%$ and the patient must have a life expectancy exceeding 5 years [36••]. These recommendations have also been supported by the European Society of Cardiology, who have reduced their threshold of acceptable complication rates following CEA and CAS from 6 to 3\%, in line with the ESVS guidelines [44, $66 \cdot \bullet$.

However, these guidelines are based on RCT findings which, due to the antiquated nature of the BMT and interventional techniques used, may not be generalisable to contemporary practise. There is therefore uncertainty regarding which technique is superior or, indeed, if advancements in BMT have replaced the need for performing carotid interventions.

In order to address this important issue, the Stent-protected Angioplasty in Asymptomatic Carotid Artery Stenosis versus Carotid Endarterectomy-2 (SPACE-2) trial was designed to compare BMT alone versus BMT with CEA versus BMT with CAS in asymptomatic patients. Unfortunately, however, due to slow recruitment of patients, the RCT was modified to compare BMT alone versus BMT with CEA and BMT alone versus $B M T$ with $C A S$, with the initial results recently being reported [67••]. In 513 asymptomatic patients, there were no peri-procedural deaths recorded following CEA or CAS $[67 \cdot 0]$. This is the first RCT to report no peri-procedural deaths following CEA and CAS [67••]. There were also no deaths or strokes within 30 days of patients being randomised to BMT whilst the combined peri-procedural stroke and death rate was $2.0 \%$ after CEA and $2.5 \%$ following CAS [67••]. These results, whilst promising, have wide confidence intervals due to the small sample size and suggest a 'missed opportunity' to clarify uncertainty in this important subject. Long-term outcomes are awaited.

Ongoing RCTs such as the Carotid Revascularisation and Medical Management for Asymptomatic Carotid Stenosis trial (CREST-2) and the European Carotid Surgery Trial (ECST2) will compare both CAS (with use of EPDs) and CEA with medical management in asymptomatic patients with severe carotid artery stenosis whilst the Endarterectomy Combined with Optimal Medical Therapy (OMT) versus OMT Alone in Patients With Asymptomatic Severe Atherosclerotic Carotid Artery Stenosis at Higher-than-average Risk of Ipsilateral Stroke (ACTRIS) trial will compare CEA, in conjunction with BMT, versus BMT alone $[68 \bullet \bullet, 69 \bullet \bullet$.
The Asymptomatic Carotid Surgery Trial-2 (ACST-2) will compare CAS with CEA for long-term stroke prevention in asymptomatic patients with severe carotid artery stenosis on BMT [70]. The ACST-2, due to complete recruitment by the end of 2019, is the largest RCT ever conducted comparing CAS with CEA and should provide reliable evidence as it is being conducted internationally with experienced collaborators and high-quality BMT in addition to modern carotid revascularisation strategies [70].

The results of these RCTs are eagerly anticipated and awaited in the 2020s as they will provide clarity, in a large number of patients (whilst also providing an opportunity for meta-analysis), regarding the effect of the increased use of statins, new stent designs and safer CAS techniques compared with CEA and BMT to better inform the management of patients with asymptomatic carotid artery stenosis.

\section{Compliance with Ethical Standards}

Conflict of Interest Kamran Gaba received a grant from the Medical Research Council, during the conduct of the study. Peter Ringleb reports personal fees from Boehringer Ingelheim, personal fees from Bayer and personal fees from Pfizer, outside the submitted work. Alison Halliday declares no potential conflict of interest.

Human and Animal Rights and Informed Consent This article does not contain any studies with human or animal subjects performed by any of the authors.

Abbreviations ACAS, Asymptomatic Carotid Atherosclerosis Trial; ACST, Asymptomatic Carotid Surgery Trial; ACT, Asymptomatic Carotid Trial; ACTRIS, Endarterectomy Combined with Optimal Medical Therapy (OMT) versus OMT Alone in Patients With Asymptomatic Severe Atherosclerotic Carotid Artery Stenosis at Higher-than-average Risk of Ipsilateral Stroke; ARR, absolute risk reduction; BMT, best medical therapy; CAS, carotid artery stenting; CEA, carotid endarterectomy; COMPASS, Cardiovascular Outcomes for People using Anticoagulation Strategies; CREST, Carotid Revascularisation Endarterectomy versus Stenting Trial; CSTC, Carotid Stenting Trialists' Collaboration; DALY, disability-adjusted life year; ECST, European Carotid Surgery Trial; EPD, embolic protection device; ESVS, European Society for Vascular Surgery; EVA-3S, Endarterectomy Versus Angioplasty in patients with Symptomatic Severe Carotid Stenosis; EVEREST, Eversion Carotid Endarterectomy versus Standard Trial; GA, general anaesthesia; GALA, General Anaesthesia versus Local Anaesthesia for Carotid surgery; ICSS, International Carotid Stenting Study; LA, local anaesthesia; LDL, low-density lipoprotein; MI, myocardial infarction; OMT, optimal medical therapy; RCT, randomised clinical trial; SAPPHIRE, Stenting and Angioplasty with Protection in Patients at High Risk for Endarterectomy; SPACE, Stent-Protected Angioplasty versus Carotid Endarterectomy; UK, United Kingdom; USA, United States of America; VA, Veterans Affairs

Open Access This article is distributed under the terms of the Creative Commons Attribution 4.0 International License (http:// creativecommons.org/licenses/by/4.0/), which permits unrestricted use, distribution, and reproduction in any medium, provided you give appropriate credit to the original author(s) and the source, provide a link to the Creative Commons license, and indicate if changes were made. 


\section{References}

Papers of particular interest, published recently, have been highlighted as:

- Of importance

•- Of major importance

1. Stroke Association. State of the nation: stroke statistics. 2018. Available at: https://www.stroke.org.uk/system/files/sotn_2018. pdf. Accessed 30 Aug 2018.

2. Murray CJL, Vos T, Lozano R, Naghavi M, Flaxman AD, Michaud C, et al. Disability-adjusted life years (DALYs) for 291 diseases and injuries in 21 regions, 1990-2010: a systematic analysis for the Global Burden of Disease Study 2010. Lancet. 2012;380(9859): 2197-223.

3. Roger VL, Go AS, Lloyd-Jones DM, Adams RJ, Berry JD, Brown TM, et al. Heart disease and stroke statistics - 2011 update: a report from the American Heart Association. Circulation. 2011;123(4): e18-e209.

4. Aichner FT, Topakian R, Alberts MJ, Bhatt DL, Haring HP, Hill $\mathrm{MD}$, et al. REACH Registry Investigators. High cardiovascular event rates in patients with asymptomatic carotid stenosis: the REACH Registry. Eur J Neurol. 2009;16(8):902-8.

5. Lewis SC, Warlow CP, Bodenham AR, Colam B, Rothwell PM, Torgerson D, et al. For the GALA Trial Collaborative Group. General Anaesthesia versus local anaesthesia for carotid surgery (GALA): a multicentre, randomised controlled trial. Lancet. 2008;372(9656):2132-42.

6. Roffi M, Mukherjee D, Clair DG. Carotid artery stenting vs endarterectomy. Eur Heart J. 2009;30(22):2693-704.

7. Cao P, Giordano G, De Rango P, Zannetti S, Chiesa R, Coppi G, et al. Eversion versus conventional carotid endarterectomy: late results of a prospective multicentre randomised trial. J Vasc Surg. 2000;31:19-30.

8. Brooks WH, McClure RR, Jones MR, Coleman TC, Breathitt L. Carotid angioplasty and stenting versus carotid endarterectomy: randomised trial in a community hospital. J Am Coll Cardiol. 2001;38:1589-95.

9. McCarthy WJ, Wang R, Pearce WH, Flinn WR, Yao JS. Carotid endarterectomy with an occluded contralateral carotid artery. Am J Surg. 1993;166(2):168-71.

10. Rothwell PM, Slattery J, Warlow CP. Clinical and angiographic predictors of stroke and death from carotid endarterectomy: systematic review. Br Med J. 1997;315(7122):1571-7.

11. Lanzino G, Mericle RA, Lopes DK, Wakhloo AK, Guterman LR, Hopkins LN. Percutaneous transluminal angioplasty and stent placement for recurrent carotid artery stenosis. J Neurosurg. 1999;90(4):688-94.

12. Mericle RA, Kim SH, Lanzino G, Lopes DK, Wakhloo AK, Guterman LR, et al. Carotid artery angioplasty and use of stents in high-risk patients with contralateral occlusions. J Neurosurg. 1999;90(6):1031-6.

13. Yadav JS, Roubin GS, King P, Iyer S, Vitek J. Angioplasty and stenting for restenosis after carotid endarterectomy. Initial experience. Stroke. 1996;27(11):2075-9.

14. Theiss W, Hermanek P, Mathias K, Bruckmann H, Dembski J, Hoffmann FJ, et al. Predictors of death and stroke after carotid angioplasty and stenting: a subgroup analysis of the Pro-CAS data. Stroke. 2008;39:2325-30.

15. Gray WA, Yadav JS, Verta P, Scicli A, Fairman R, Wholey M, et al. The CAPTURE registry: predictors of outcomes in carotid artery stenting with embolic protection for high surgical risk patients in the early post-approval setting. Catheter Cardiovasc Interv. 2007;70: 1025-33.
16. Zahn R, Ischinger T, Hochadel M, Zeymer U, Schmalz W, Treese $\mathrm{N}$, et al. Carotid artery stenting in octogenarians: results from the ALKK Carotid Artery Stent (CAS) Registry. Eur Heart J. 2007;28: 370-5.

17. Fiehler J, Jansen O, Berger J, Eckstein HH, Ringleb PA, Stingele R. Differences in complication rates among the centres in the SPACE study. Neuroradiology. 2008;50:1049-53.

18. Calvet D, Mas J-L, Algra A, Becquemin J-P, Bonati LH, Dobson J, et al. For the Carotid Stenting Trialists' Collaboration. Carotid stenting: is there an operator effect? A pooled analysis from the Carotid Stenting Trialists' Collaboration. Stroke. 2014;45(2):527-32.

19. Mas J-L, Chatellier G, Beyssen B, Branchereau A, Moulin T, Becquemin J-P, et al. For the EVA-3S Investigators. Endarterectomy versus stenting in patients with symptomatic severe carotid stenosis. N Engl J Med. 2006;355:1660-71.

20. Ringleb PA, Allenberg J, Brückmann H, Eckstein HH, Fraedrich G, Hartmann M, et al. The SPACE Collaborative Group. 30 day results from the SPACE trial of stent-protected angioplasty versus carotid endarterectomy in symptomatic patients: a randomised noninferiority trial. Lancet. 2006;368(9543):1239-47.

21. Ederle J, Dobson J, Featherstone RL, Bonati LH, van der Worp HB, de Borst GJ, et al. International Carotid Stenting Study investigators. Carotid artery stenting compared with endarterectomy in patients with symptomatic carotid stenosis (International Carotid Stenting Study): an interim analysis of a randomised controlled trial. Lancet. 2010;375(9719):985-97.

22. Hobson RW, Weiss DG, Fields WS, Goldstone J, Moore WS, Towne JB, et al. Efficacy of carotid endarterectomy for asymptomatic carotid stenosis. N Engl J Med. 1993;328:221-7.

23. ACAS Investigators. Endarterectomy for asymptomatic carotid artery stenosis. Executive Committee for the Asymptomatic Carotid Atherosclerosis Study. JAMA. 1995;273:1421-8.

24. Halliday A, Mansfield A, Marro J, Peto C, Peto R, Potter J, et al. Prevention of disabling and fatal strokes by successful carotid endarterectomy in patients without recent neurological symptoms: randomised controlled trial. Lancet. 2004;363:1491-502.

25. Halliday A, Harrison M, Hayter E, Kong X, Mansfield A, Marro J, et al. 10-year stroke prevention after successful carotid endarterectomy for asymptomatic stenosis (ACST-1): a multicentre randomised trial. Lancet. 2010;376(9746):1074-84.

26. Yadav JS, Wholey MH, Kuntz RE, Fayad P, Katzen BT, Mishkel GJ, et al. For the Stenting and Angioplasty with Protection in Patients at High Risk for Endarterectomy Investigators. Protected carotid artery stenting versus endarterectomy in high-risk patients. N Engl J Med. 2004;351(15):1493-501.

27. Gurm HS, Yadav JS, Fayad P, Katzen BT, Mishkel GJ, Bajwa TK, et al. For the SAPPHIRE Investigators. Long-term results of carotid stenting versus endarterectomy in high-risk patients. N Engl J Med. 2008;358(15):1572-9.

28. Brott TG, Hobson RW II, Howard G, Roubin GS, Clark WM, Brooks W, et al. Stenting versus endarterectomy for treatment of carotid artery stenosis. N Engl J Med. 2010;363(1):11-23.

29.• Brott TG, Howard G, Roubin GS, Meschia JF, Mackey A, Brooks $\mathrm{W}$, et al. for the CREST Investigators. Long-term results of stenting versus endarterectomy for carotid artery stenosis. $N$ Engl J Med. 2016;374(11):1021-31. Important RCT comparing CEA and CAS.

30. Lal BK, Roubin GS, Lutsep HL, Moore WS, Malas MB, Chiu D, et al. For the CREST Investigators. Restenosis after carotid artery stenting and endarterectomy: a secondary analysis of CREST, a randomised controlled trial. Lancet Neurol. 2012;11:755-63.

31.• Rosenfield K, Matsumura JS, Chaturvedi S, Riles T, Ansel GM, Metzger C, et al. The ACT I Investigators. Randomised trial of stent versus surgery for asymptomatic carotid stenosis. $N$ Engl J Med. 2016;374:1011-20. Important RCT comparing CEA and CAS. 
32.• Paraskevas KI, Mikhailidis DP, Veith FJ, Spence JD. Definition of best medical treatment in asymptomatic and symptomatic carotid artery stenosis. Angiology. 2016;67(5):411-9. Update regarding BMT in asymptomatic patients.

33. Collins R, Armitage J, Parish S, Sleight P, Peto R. The Heart Protection Study Collaborative Group. Effects of cholesterollowering with simvastatin on stroke and other major vascular events in 20536 people with cerebrovascular disease or other high-risk conditions. Lancet. 2004;363(9411):757-67.

34. Heart Protection Study Collaborative Group. Randomized trial of the effects of cholesterol-lowering with simvastatin on peripheral vascular and other major vascular outcomes in 20,536 people with peripheral vascular disease and other high-risk conditions. J Vasc Surg. 2007;45(4):653-4.

35. Amarenco P, Bogousslavsky J, Callahan A 3rd, Goldstein LB, Hennerici M, Rudolph AE, et al. The Stroke Prevention by Aggressive Reduction in Cholesterol Levels (SPARCL) Investigators. High-dose atorvastatin after stroke or transient ischaemic attack. New Engl J Med. 2006;355(6):549-59.

36.• Naylor AR, Ricco JB, de Borst GJ, Debus S, de Haro J, Halliday A, et al. Editor's choice - management of atherosclerotic carotid and vertebral artery disease: 2017 clinical practice guidelines of the European Society for Vascular Surgery (ESVS). Eur J Vasc Endovasc Surg. 2018;55(1):3-81. Very useful recent guidelines.

37. Baigent C, Blackwell L, Collins R, Emberson J, Godwin J, Peto R, et al. Antithrombotic Trialists' (ATT) Collaboration. Aspirin in the primary and secondary prevention of vascular disease: collaborative meta-analysis of individual participant data from randomised trials. Lancet. 2009;373(9678):1849-60.

38. King A, Shipley M, Markus H, ACES Investigators. The effect of medical treatments on stroke risk in asymptomatic carotid stenosis. Stroke. 2013;44(2):542-6.

39.• Park J-M, Kang K, Cho Y-J, Hong K-S, Lee K-B, Park TH, et al. CRCS-5 Investigators. Comparative effectiveness of pre-stroke aspirin on stroke severity and outcome. Ann Neurol. 2016;79(4):560 8. The role of aspirin in stroke prevention.

40. Bhatt DL, Flather MD, Hacke W, Berger PB, Black HR, Boden WE, et al. CHARISMA Investigators. Patients with prior myocardial infarction, stroke or symptomatic peripheral arterial disease in the CHARISMA trial. J Am Coll Cardiol. 2007;49(19):1982-8.

41. Taylor F, Huffman MD, Macedo AF, Moore THM, Burke M, Davey Smith G, et al. Statins for the primary prevention of cardiovascular disease. Cochrane Database Syst Rev. 2013;1:CD004816.

42. Baigent C, Keech A, Kearney PM, Blackwell L, Buck G, Pollicino C, et al. Cholesterol Treatment Trialists' (CTT) Collaborators. Efficacy and safety of cholesterol-lowering treatment: prospective meta-analysis of data from 90,056 participants in 14 randomised trials of statins. Lancet. 2005;366(9493):1267-78.

43. Stone NJ, Robinson JG, Lichtenstein AH, Bairey Merz CN, Blum $\mathrm{CB}$, Eckel RH, et al. American College of Cardiology/American Heart Association Task Force on Practice Guidelines. 2013 ACC/ AHA guideline on the treatment of blood cholesterol to reduce atherosclerotic cardiovascular risk in adults: a report of the American College of Cardiology/American Heart Association Task Force on Practice Guidelines. J Am Coll Cardiol. 2014;63(25 Pt B):2889-934.

44. Tendera M, Aboyans V, Bartelink M-L, Baumgartner I, Clément D, Collet J-P, et al. ESC guidelines on the diagnosis and treatment of peripheral artery diseases: document covering atherosclerotic disease of extracranial carotid and vertebral, mesenteric, renal, upper and lower extremity arteries: the Task Force on the Diagnosis and Treatment of Peripheral Artery Diseases of the European Society of Cardiology (ESC). Eur Heart J. 2011;32(22):2851-906.

45. Sutton-Tyrrell K, Wolfson SK Jr, Kuller LH. Blood pressure treatment slows the progression of carotid stenosis in patients with isolated systolic hypertension. Stroke. 1994;25(1):44-50.
46. Law MR, Morris JK, Wald NJ. Use of blood pressure lowering drugs in the prevention of cardiovascular disease: meta-analysis of 147 randomised trials in the context of expectations from prospective epidemiological studies. BMJ. 2009;338:b1665.

47. Huo Y, Li J, Qin X, Huang Y, Wang X, Gottesman RF, et al. CSPPT Investigators. Efficacy of folic acid therapy in primary prevention of stroke among adults with hypertension in China: the CSPPT randomized clinical trial. JAMA. 2015;313(13):1325-35. The role of blood pressure control in stroke prevention.

48. Neal B, MacMahon S, Chapman N. Blood Pressure Lowering Treatment Trialists' Collaboration. Effects of ACE inhibitors, calcium antagonists, and other blood-pressure-lowering drugs: results of prospectively designed overviews of randomised trials. Blood Pressure Lowering Treatment Trialists' Collaboration. Lancet. 2000;356(9246):1955-64.

49. Banerjee C, Moon YP, Paik MC, Rundek T, Mora-McLaughlin C, Vieira JR, et al. Duration of diabetes and risk of ischaemic stroke: the Northern Manhattan Study. Stroke. 2012;43(5):1212-7.

50. Gaede P, Lund-Andersen H, Parving HH, Pedersen O. Effect of a multifactorial intervention on mortality in type 2 diabetes. $\mathrm{N}$ Engl $\mathrm{J}$ Med. 2008;358(6):580-91.

51. UK Prospective Diabetes Study Group. Tight blood pressure control and risk of macrovascular and microvascular complications in type 2 diabetes: UKPDS 38. BMJ. 1998;317(7160):703-13.

52. ESH/ESC Task Force for the Management of Arterial Hypertension. 2013 Practice guidelines for the management of arterial hypertension of the European Society of Hypertension $(\mathrm{ESH})$ and the European Society of Cardiology (ESC): ESH/ESC Task Force for the Management of Arterial Hypertension. J Hypertens. 2013;31(10):1925-38.

53. Hannan EL, Popp AJ, Feustel P, Halm E, Bernardini G, Waldman J, et al. Association of surgical specialty and processes of care with patient outcomes for carotid endarterectomy. Stroke. 2001;32(12): 2890-7.

54. AbuRahma AF, Srivastava M, Hass SM, Chong B, AbuRahma Z, Dean LS, et al. Practice patterns of carotid endarterectomy as performed by different specialties at a single institution and the effect on perioperative stroke and cost of preoperative imaging. J Vasc Surg. 2014;60(5):1232-7.

55. Enomoto LM, Hill DC, Dillon PW, Han DC, Hollenbeak CS. Surgical specialty and outcomes for carotid endarterectomy: evidence from the National Surgical Quality Improvement Program. J Surg Res. 2014;188(1):339-48.

56. Hussain MA, Mamdani M, Tu JV, Saposnik G, Salata K, Bhatt DL, et al. Association between operator specialty and outcomes after carotid artery revascularization. J Vasc Surg. 2018;67(2):478-89. Effect of specialty on outcome following CEA and CAS.

57. Timaran CH, Mantese VA, Malas M, Brown OW, Lal BK, Moore WS, et al. For the CREST Investigators. Differential outcomes of carotid stenting and endarterectomy performed exclusively by vascular surgeons in the Carotid Revascularization Endarterectomy versus Stenting Trial (CREST). J Vasc Surg. 2013;57(2):303-8.

58. Ruby ST, Robinson D, Lynch JT, Mark H. Outcome analysis of carotid endarterectomy in Connecticut: the impact of volume and specialty. Ann Vasc Surg. 1996;10(1):22-6.

59. Mattos MA, Modi JR, Mansour AM, Mortenson D, Karich T, Hodgson KJ, et al. Evolution of carotid endarterectomy in two community hospitals: seventeen years and 2243 operations later. J Vasc Surg. 1995;21(5):719-26.

60. Phillips P, Poku E, Essat M, Woods HB, Goka EA, Kaltenthaler EC, et al. Systematic review of carotid artery procedures and the volume-outcome relationship in Europe. Br J Surg. 2017;104(10): 1273-83. Volume-outcome relationship in CEA and CAS.

61. Hopkins LN, Roubin GS, Chakhtoura EY, Gray WA, Ferguson RD, Katzen BT, et al. The Carotid Revascularization Endarterectomy versus Stenting Trial: credentialing of interventionalists and final 
results of lead-in phase. J Stroke Cerebrovasc Dis. 2010;19(2):15362.

62. Kastrup A, Groschel K, Krapf H, Brehm BR, Dichgans J, Schulz JB. Early outcome of carotid angioplasty and stenting with and without cerebral protection devices: a systematic review of the literature. Stroke. 2003;34:813-9.

63. Zahn R, Mark B, Niedermaier N, Zeymer U, Limbourg P, Ischinger $\mathrm{T}$, et al. Embolic protection devices for carotid artery stenting: better results than stenting without protection? Eur Heart J. 2004;25: $1550-8$.

64.• Anand SS, Bosch J, Eikelboom JW, Connolly SJ, Diaz R, Widimsky P, et al. Rivaroxaban with or without aspirin in patients with stable peripheral or carotid artery disease: an international, randomised, double-blind, placebo-controlled trial. Lancet. 2018;391:219-29. Subgroup analysis of patients with asymptomatic carotid stenosis in the COMPASS trial.

65.• Cui L, Han Y, Zhang S, Liu X, Zhang J. Safety of stenting and endarterectomy for asymptomatic carotid artery stenosis: a metaanalysis of randomised controlled trials. Eur J Vasc Endovasc Surg. 2018;55:614-24. https://doi.org/10.1016/j.ejvs.2018.02.020. Recent meta-analysis investigating peri-procedural outcomes following CEA and CAS.

66.• Aboyans V, Ricco J-B, Bartelink M-LEL, Björck M, Brodmann M, Cohnert T, et al. 2017 ESC guidelines on the diagnosis and treatment of peripheral arterial diseases, in collaboration with the European Society for Vascular Surgery (ESVS): Document covering atherosclerotic disease of extracranial carotid and vertebral, mesenteric, renal, upper and lower extremity arteries. Endorsed by: the European Stroke Organisation (ESO). The Task Force for the Diagnosis and Treatment of Peripheral Arterial Diseases of the European Society of Cardiology (ESC) and of the European Society for Vascular Surgery (ESVS). Eur Heart J. 2018;39(9):763-816. Very useful recent guidelines.

67.• Eckstein H-H, Reiff T, Ringleb P, Jansen O, Mansmann U, Hacke W, et al. SPACE-2: a missed opportunity to compare carotid endarterectomy, carotid stenting and best medical treatment in patients with asymptomatic carotid stenoses. Eur J Vasc Endovasc Surg. 2016;51(6):761-5. RCT comparing CEA, CAS and BMT.

68.• Gaba K, Halliday A. Epidemiology and indications for revascularization of carotid stenoses. In: Faggioli G, Halliday A, Pini R, Gallitto E, Stella A, editors. Carotid Disease: Clinical and morphological insights. Turin: Edizioni Minerva Medica S.p.A.; 2017. Recent update on indications for CEA and CAS in symptomatic and asymptomatic patients.

69.• Morris DR, Ayabe K, Inoue T, Sakai N, Bulbulia R, Halliday A, et al. Evidence-based carotid interventions for stroke prevention: state-of-the-art review. J Atheroscler Thromb. 2017;24(4):373-87. Recent update on indications for CEA and CAS in symptomatic and asymptomatic patients and an overview of relevant guidelines.

70. Halliday A, Bulbulia R, Gray W, Naughten A, den Hartog A, Delmestri A, et al. ACST-2 Collaborative Group. Status update and interim results from the asymptomatic carotid surgery trial-2 (ACST-2). Eur J Vasc Endovasc Surg. 2013;46(5):510-8. 